\title{
AMBIGUITAS PADA SLOGAN IKLAN KELUARGA BERENCANA, GOOD DAY, TEA JUS, SARIWANGI, FLORIDINA, TOLAK ANGIN, BUKALAPAK, DAN ONE PUSH VAPE
}

\author{
Ibnu Kurnia Bakti, Milam Oktavianti, Nun Ainun, dan Winda Puspita \\ Universitas Negeri Malang \\ Email: milamoktavianti@gmail.com
}

\begin{abstract}
ABSTRAK: Iklan adalah berita pesanan untuk mendorong, membujuk khalayak ramai agar tertarik pada barang dan jasa yang ditawarkan. Iklan tidak hanya terbatas untuk menjual barang agar laku di pasaran, melainkan iklan juga digunakan sebagai sarana himbauan dan penyampai pesan. Untuk lebih menarik khalayak, iklan biasanya memakai slogan. Slogan adalah perkataan atau kalimat pendek yang menarik atau mencolok untuk mudah diingat oleh kalangan masyarakat. Artikel ini bertujuan untuk mengetahui makna mabiguitas pada slogan iklan,seperti iklan “Keluarga Berencana, Good Day, Tea Jus, Sariwangi, Floridina, dan Tolak Angin" dll. Pada iklan yang kami analisis ini menemukan banyak sekali kata-kata amupun makna-makna yang ambguitas baik itu di ucapakan secara lisan atau muncul maknanya tersendiri.
\end{abstract}

Kata Kunci: Ambigitas Makna, Slogan Iklan,Televisi.

\section{PENDAHULUAN}

Kegandaan makna dalam kata ambiguitas berasal dari satuan gramatikal yang lebih besar, yaitu frase atau kalimat, terjadi sebagai akibat penafsiran struktur gramatikal (Charmelia, 2014: 2). makna kata Ambiguitas dapat terjadi pada iklan yang banyak beredar pada masyarakat melalui media cetak maupun online. Ambiguitas berasal dari bahasa Inggris yaitu ambiguity yang berarti suatu konstruksi yang dapat ditafsirkan lebih dari satu arti. Ambiguitas sering juga disebut ketaksaan (Alwi, 2002:36). Yang dimaksud dengan ketaksaan dapat diartikan atau ditafsirkan memiliki lebih dari satu makna akan sebuah konstruksi sintaksis. Sedangkan yang dimaksud dengan iklan adalah suatu proses komunikasi yang bertujuan untuk membujuk atau menggiring orang untuk mengambil tindakan yang menguntungkan bagi pihak pembuat iklan” (Durianto, 2003).

Iklan yang sering muncul di dalam televisi ataupun media cetak banyak sekali mengunakan kata-kata yang ambiguitas karena didalam iklan televisi, sering sekali 
mengunakan tuturan berbahasa,baik itu bahasa yang mudah dipahami ataupun bahasa yang bisa dikondisikan dengan keadaan jaman . sehingga Bahasa merupakan sarana penting dalam suatu interaksi sosial,baik sebagai sarana interaksi sosial bahasa mampu menyampaikan informasi dari manusia yang satu pada manusia yang lain. Sehingga bahasa Sebagai alat komunikasi, dikerna bahasa itu terdiri atas dua bagian, yaitu bentuk atau lambang yang berupa ujaran-ujaran dan makna. Pada iklan televisi yang disiarkan secara langsung ataupun lewar media lain, iklan tidak semata-mata menyampaikan tuturan berbahasa saja ,melainkan bisa melalui gambar atau betuk yang unik yang bisa menarih perhatian penonton di ikuti oleh musik yang mempurkuat simbol atau cerita yang ingin di tampilkan oleh produk pada iklan tersebut. Pada iklan TV maupun online dan cetak mengunakan kata slogan, karena kata slogan mudah memperingat masyrakata yang disampaikan oleh iklan tersebut seperti solo berserih (bersih, sedaht, indah, rapi), sehingga dengan mengunakan kalimat slogan akan mempercepat terkenal suatu produk yang diiklankan apabila memiliki kalimat slogan yang baik. Artikel ini betujuan untuk menelaah lagi mengenai bentuk kata ambiguitas pada slogan iklan televisi dan mengkaji kembali makna ambiguitas yang dipaparkan pada iklan.

\section{PEMBAHASAN}

Ambiguitas sering diartikan sebagai kata yang bermakna ganda atau mendua arti. Kegandaan makna dalam ambiguitas berasal dari satuan gramatikal yang lebih besar, yaitu frase atau kalimat, dan terjadi sebagai akibat penafsiran struktur gramatikal (Chaer dalam Charmelia, 2013: 6). Ambiguitas dibagi menajadi tiga jenis, diantaranya: (1) ambiguitas gramatikal, (2) ambiguitas fonetik, dan (3) ambiguitas leksikal. Ambiguitas gramatikal terjadi karena dipengaruhi oleh adanya imbuhan yang terdapat dalam suatu kata. Ambiguitas fonetik disebabkan oleh membaurnya bunyi-bunyi bahasa yang diujarkan. Sedangkan ambiguitas leksikal disebabkan karena suatu kata memiliki banyak arti sesuai dengan lingkungan pembaca/penulis.

Menurut Pateda (2010:201), menyatakan bahwa gagasan yang akan disampaikan oleh orang lain menlalui media massa terkadang membuat pendengar atau pembaca sulit tuntuk memahami apa yang diujarkan maupun dibaca (Pateda, 2010:201). Misalnya, pada slogan iklan keluarga berencana, yang berbunyi “ duan anak lebih baik” Slogan tersebut dapat memunculkan keanekaan tafsiran makna yang bisa membuat ketaksaan atau ambiguitas. Sehingga Untuk menghindari ambiguitas secara lisan, orang harus bertanya lagi kepada pembicara, dan memang inilah sikap yang sebaiknya dilaksanakan, sedangkan untuk menghindari ambiguitas secara tertulis, orang harus mengetahui betul konteks yang ada pada 
tulisan. Sehingga Pada iklan TV yang sering kita jumpai, yang Berkaitan dengan ambiguitas mengandung unsur ambiguitas/kegandaan makna. Hal tersebut bisa disengaja atau tidak, karena bahasa yang digunakan dalam iklan bertujuan untuk menarik khalayak agar membeli produk-produk yang ditawarkan, misalnya seperti iklan tolak angin. Dan pada artikel ini kami akan membahas lebih lanjut lagi mengenai keambiguian pada iklan layanan masyarakat yang disiarkan disetiap chanel TV.

\section{Ambiguitas pada Iklan Keluarga Berencana (KB)}

Iklan masyarakat yang memiliki slogan "Dua anak lebih baik" tentunya sudah tidak asing lagi di telinga sebagian besar masyarakat Indonesia. Tetapi cara penyampaian dan tulisan pada iklan tersebut yang ambigu dapat memutar balikkan pikiran orang-orang yang mendengarnya. Ada dua makna yang dapat ditimbulkan oleh kalimat ini yakni dijelaskan sebagai berikut.

Pertama, "dua anak, lebih baik". Maksud dari kalimat tersebut yaitu memiliki dua anak lebih baik daripada memiliki lebih dari dua anak. Karena Indonesia merupakan negara yang tingkat kepadatan penduduknya menduduki nomer empat dunia, iklan tersebut disampaikan bertujuan untuk menghimbau masyarakat Indonesia untuk cukup memiliki dua orang anak saja.

Kedua, "dua anak lebih, baik". Maksud dari kalimat tersebut yaitu memiliki lebih dari dua orang anak adalah baik. Jika iklan tersebut ditafsirkan seperti itu oleh masyarakat Indonesia, maka usaha pemerintah dalam mengurangi kepadatan penduduk di Indonesia otomatis sia-sia dan masyarakat Indonesia akan memiliki anggapan bahwa memiliki lebih dari dua orang anak itu dianjurkan oleh pemerintah.

Iklan tersebut dapat ditemukan dalam bahasa lisan maupun tulisan. Tetapi, baik keduanya yaitu bahasa lisan maupun tulisan tetap ditemukan keambiguan. Ditemukan keambiguan dalam bahasa tulisan karena tanda baca atau penanda-penanda ejaan tidak lengkap diberikan dan kurang jelas, dan ditemukan keambiguan dalam bahasa lisan karena dalam menyampaikan iklan tersebut penjedaan intonasi kurangditekankan pada salah satu aspeknya. Keambiguan dalam iklan layanan masyarakat tersebut dapat dihindari apabila dalam penulisannya diikuti oleh tanda baca yang jelas dan dalam penyampain lisannya diikuti oleh penjedaan secara jelas yang menekankan pada salah satu aspek saja.

\section{Ambiguitas pada Iklan Kopi Good Day}

Iklan kopi yang satu ini tentunya juga tidak asing lagi di telinga para remaja Indonesia. Kalimatnya yang disusun dan diolah dengan kreatif dan menarik dapat menimbulkan rasa 
penasaran untuk mencoba kopi good day tersebut ketika kita mendengarkan iklan kopi tersebut. Iklan yang berbunyi "Manisnya kopi Good Day, bikin hari-harimu makin berwarna. Selalu ada kejutan di tiap cangkirnya. Kopi Good Day - Karena Hidup Perlu Banyak Rasa!'. Banyak keambiguan yang terdapat dalam tiap-tiap kalimat yang terdapat dalam iklan tersebut. Keambiguan yang terdapat dalam tiap-tiap kalimat yang terda mpat dalam iklan tersebut yaitu:

Pertama, "manisnya kopi Good Day, bikin hari-harimu makin berwarna". Maksud warna yang terdapat dalam kalimat iklan tersebut sangat ambigu. Kata "warna" dan "harihari” yang dimaksud pada slogan ini juga bermakna ambigu. Membuat hari-hari semakin berwarna karena bertemu orang-orang baru dengan berbagai sifat dan karakter atau berwarna dalam artien karena dalam sehari-hari kita berganti pakaian dengan berbagai macam warna. Kalimat tersebut juga dapat ditafsirkan oleh masyarakat dalam bentuk pengimajinasian, seperti masyarakat dapat membayangkan bahwa hari-hari yang berwarna itu berarti hari-hari yang dikelilingi oleh pelangi yang di mana-mana kita dapat melihat pelangi yang berwarnawarni. Sehingga kalimat tersebut multitafsir jika tidak diperjelas maksud yang disampaikan.

Kedua, "selalu ada kejutan di tiap cangkirnya". Maksud yang akan disampaikan kepada khalayak dalam kalimat tersebut juga sangat tidak jelas dan ambigu. Hal tersebut dapat menimbulkan multitafsir terhadap masyarakat luas. "Selalu ada kejutan di tiap cangkirnya", hal tersebut akan berbeda jika masyarakat menggunakan cangkir dalam meminum kopi tersebut, sehingga poin "kejutan" akan hilang dalam persepsi masyarakat.

Makna yang kedua yaitu "kejutan" yang dimaksud dalam secangkir kopi good day tidak cukup jelas kejutan yang dimaksud. Makna ambigu ketiga yang terdapat dalam kalimat tersebut yaitu kejutan rasa yang berbeda-beda dalam varian rasa kopi good day. Jika yang dimaksudkan oleh iklan tersebut adalah makna yang ketiga, maka seharusnya diperjelas dengan menggantinya dengan kalimat "selalu ada kejutan rasa baru dalam tiap varian kopi good day".

Ketiga, "Karena Hidup Perlu Banyak Rasa!”. Slogan yang terdapat dalam iklan tersebut juga mengandung makna yang ambigu pada kata "rasa". Rasa dapat dipersepsikan sebagai rasa yang mencakup emosi pada seseorang, seperti kecewa, sedih, senang, dan marah. Maksud kedua yang terdapat dalam slogan iklan kopi good day tersebut yaitu karena dalam hidup perlu merasakan banyak varian rasa kopi good day yang bermacam-macam. Seperti yang terlihat pada iklan yaitu kopi good day memiliki banyak varian rasa. Maksud slogan pada iklan good day yang ketiga yang dapat ditafsirkan oleh masyarakat luas yaitu masyarakat dapat menafsirkan kata "rasa" pada slogan tersebut sebagai rasa yang dapat dicecap oleh lidah, yaitu rasa manis, asin, pahit, dan asam. 


\section{Ambiguitas pada Iklan Tea Jus}

Minuman Tea Jus sudah banyak dikenal oleh masyarakat luas. Hal tersebut tidak lepas dari peran media yang menyiarkan iklan mengenai minuman Tea Jus. Minuman ini memiliki slogan yaitu "Nikmat Teh Aslinya Paling Mantap. Pada slogan tersebut, masyarakat seakanakan diberi keyakinan bahwa teh yang diminum merupakan teh yang paling enak. Namun, pada slogan tersebut terdapat keambiguan dalam pemaknaanya. Ketaksaan tersebut dijelaskan sebagai berikut.

Pertama, slogan tersebut dapat dipersepsikan sebagai "Nikmat Teh, Aslinya Paling Mantap". Pada persepsi yang pertama ini, dapat diartikan bahwa nikmat dari teh yang disajikan memiliki rasa yang paling enak dari pada teh yang lainya.

Kedua, slogan tersebut dapat dipersepsikan sebagai "Nikmat Teh Aslinya, Paling Mantap". Pada pandangan tersebut, dapat diartikan bahwa nikmat dari teh yang asli memang paling enak.

Masing-masing persepsi yang telah dijabarkan tersebut dapat dikatakan rasional, karena slogan tersebut hanya berbeda letak tanda koma. Namun, meskipun memiliki perbedaan letak tanda koma, hal tersebut bisa saja membuat masyarakat yang membaca slogan tersebut salah paham.

\section{Ambiguitas pada Iklan Floridina}

Minuman Floridina merupakan minuman rasa jeruk yang banyak dikenal oleh masyarakat luas. Minuman Floridina memiliki slogan "Orange No. 1 di Dunia". Slogan tersebut memiliki dua pandangan yang berbeda. Hal tersebut tidak disebabkan oleh tanda baca, melainkan makna yang tersirat pada slogan tersebut.

Pertama, kata "orange" yang dimaksud pada slogan tersebut dapat diartikan dari bahasa Inggris yaitu “jeruk”. Maka dari itu, slogan tersebut dapat diartikan bahwa jeruk yang dipakai merupakan jeruk nomor satu di dunia.

Kedua, kata "orange" yang dimaksud pada slogan tersebut dapat diartikan sebagai "minuman jeruk". Sehingga, dapat diartikan bahwa minuman jeruk yang dikonsumsi masyarakat adalah minuman jeruk nomor satu di dunia.

Kedua makna tersebut dapat dikatakan rasional, tergantung bagaimana masyarakat mengartikan slogan tersebut. Namun, akan lebih baik jika slogan tersebut bisa ditulis dengan jelas supaya tujuan yang disampaikan pun jelas.

\section{Ambiguitas pada Iklan Sariwangi}


Teh Sariwangi merupakan teh yang sangat dikenal oleh masyarakat. Namun, tak banyak masyarakat yang menyadari bahwa slogan "Teh Berkualitas Pilihan Indonesia" memiliki keambiguaan. Keambiguan yang ditimbulkan oleh slogan tersebut adalah dari segi makna pada kata "teh berkualitas".

Pertama, slogan "Teh Berkualitas Pilihan Indonesia" memiliki arti bahwa teh yang digunakan merupakan teh pilihan, yaitu teh yang memiliki kualitas bagus, sehingga menjadi pilihan Indonesia.

Kedua, slogan "Teh Berkualitas Pilihan Indonesia" memiliki arti bahwa teh yang digunakan merupakan teh asli Indonesia yang memang sudah berkulitas. Dapat dikatakan bahwa teh tersebut menjadi ikon dari Indonesia, sehingga menyebutkan bahwa teh tersebut pilihan Indonesia.

Dapat disimpulkan bahwa kedua makna tersebut bisa saling terterima, hanya tergantung masyarakat memilih pilihan pertama atau pilihan kedua sebagai makna dari slogan tersebut.

\section{Ambiguitas pada Iklan Tolak Angin}

Iklan Tolak Angin memiliki slogan yang khas yaitu "Orang Pintar Minum Tolak Angin". Slogan pada iklan tersebut juga dapat dikatakan multitafsir. Hal tersebut disebabkan karena dapat diartikan menjadi beberapa makna. Keambiguan tersebtu dijabarkan sebagai berikut.

Pertama, slogan tersebut memiliki makna bahwa orang yang pintar memang selalu minum tolak angin. Ha tersebut dikarenakan orang pintar bisa saja memilih obat herbal yang lebih aman dikonsumsi. Selain itu, bentuknya yang khas yaitu cair dan dikemas dalam bentuk sachet membuat lebih mudah dikonsumsi.

Kedua, slogan tersebut memiliki makna bahwa orang yang minum tolak angin bisa menjadi pintar. Hal tersebut bisa saja diartikan begitu jika intonasi yang diucapkan berbeda. Hal tersebut juga dibuktikan dengan jika masyarakat yang meminum tolak angin akan menjadi pintar karena obat herbal diketahui tidak memiliki efek samping dibandingkan obat kimia.

\section{Ambiguitas pada Iklan BukaLapak Nego Cincaie}

Iklan Bukalapak Nego Cincai merupakan iklan yang berdurasi 1 menit dengan latar belakang pintu khas arsitektur Tionghoa, Iklan ini ditayangkan bersamaan dengan perayaan hari raya Tahun Baru Imlek yang dirayakan oleh masyarakat keturunan Tionghoa di Indonesia. pada iklan ini banyak sekali mengunakan kata-kata yang ambiguitas atau tidak 
tepat, seperti teks berikut ini "Ayo ayoo semua yang dinego bisa dinego. Bisa dilihat analisis ambigunya iklan ini.

Pertaman, masyarakat akan menggira bahwa pada teks ini“Ayo aуoo semua yang dinego bisa dinego" mengatakan barang yang dijual di bukalapak bisa dinego dan dinego lagi atau prediksi ke dua.

Kedua, pada iklan ini mempunyai barang-barang yag murah apalagi harganya bisa dinego. Sehingga pada kedua analisis diatas menemukan keambiguitasnya makna teks iklan Bukalapak Nego Cincaie.

\section{Ambiguitas pada Iklan One PushVape Semprot Satu Detik Bebas Nyamuk Sepuluh Jam}

Pada data teks iklan di atas terdapat slogan "One PushVape Semprot Satu Detik Bebas Nyamuk Sepuluh Jam" pernyataan tersebut mengandung ketaksaan atau ambigu, karena dapat diartikan.

Pertama, masyarakat akan berpikir bahwa dengan mengunakan "One PushVape Semprot Satu Detik Bebas Nyamuk Sepuluh Jam” akan mengabitakan nyamuk Mampus vape semprot satu detik bebas nyamuk sepuluh jam.

Kedua, One pushvape semprot satu detik bebas nyamuk sepuluh jam. Kedua makna di atas adalah makna yang dapat ditimbulkan oleh ungkapan iklan tersebut. Maksud yang dituju oleh iklan tersebut adalah makna yang ada dalam poin 2, yaitu one pushvape semprot satu detik bebas nyamuk sepuluh jam

\section{SIMPULAN}

Berdasarkan hasil analisis pada pembahasan pada teks iklan di atas,dapat kami simpulkan bahwa, makna ambiguitas yang terkemas dalam suatu pesan sering kali terjadi kesalahan baik itu pesan yag dibuat agar masyarakat terkesan atau pesan yang memang segaja dibuat ambiguitas, dikarenakan dengan mengunakan kata-kata yang ambiguitas pada setiap iklan akan memudah penonton untuk menghafalnya, selain itu juga akan mudah untuk di mengginggat terhadap nama-nama produk yang akan di iklankan di setiap Chanel TV. Sehingga menimbulkan Banyak kesalahan-kesalahan berbahasa yang dapat ditemukan dalam iklan-iklan. Produk yang akan di iklankan akan terlihat menarik jika dibuat sebagus mungkin dengan mengikuti trendingnya zaman, sehingga dengan mengunakan bahasa yang kurang tepat pun akan tidak berpengaruh sekalipun, karena masyarakan akan yang d iklan akan lebih fokus pada gambar-gambar yang terlihat menarik itu. Oleh karena itu masyarakat dituntut untuk lebih jeli dalam memilih produk atau jasa yang ada dalam iklan-iklan. Jangan sampai masyarakat tertipu oleh bahasa-bahasa iklan yang sangat menggoda. 


\section{DAFTAR RUJUKAN}

Charmelia, E. O., 2014. Ambiguitas Frasa Nomina Pada Judul Artikel Surat Kabar Harian Solopos September-Oktober 2013. Jurnal UMS,

Durianto, Sugiarto, Widjaja dan Supraktino. dua003. Invasi Pasar Dengan Iklan Yang Efektif. Gramedia Pustaka Utama. Jakarta.

Pateda, Mansur. 2010. Semantik, Jakarta: Rineka Cipta. 